\title{
The response of clinical practice curriculum in teacher education to the Covid-19 breakout: A case study from Israel
}

\author{
Linor L. Hadar ${ }^{1} \mathbb{D} \cdot$ Bracha Alpert $^{1} \cdot$ Tamar Ariav $^{1}$
}

Accepted: 30 September 2020 / Published online: 24 November 2020

(C) UNESCO IBE 2020

\begin{abstract}
This case study explores how teacher education curriculum in a college in Israel responded to the Covid-19 outbreak. The article focuses on the clinical component of the preservice curriculum (practice teaching and methods courses). It reveals that curriculum became malleable in two major ways: there was (1) a shift to learner-centered wellbeing and social emotional learning (SEL); and (2) an adaptation of teaching methods. The Covid-19 shutdown imposed a restructuring of the content, sequence, and scope of the curriculum. While certain topics were omitted or reduced in scope, others-especially those related to digital instruction-were introduced or expanded. Pedagogy instructors also began to attend to their students' well-being by introducing SEL contents and activities. This response during challenging times revealed teacher educators' adaptability, resilience, and agency. The Covid-19 breakout transformed the curriculum from a traditional preplanned and structured syllabus to one that is more responsive, dynamic, and malleable.
\end{abstract}

Keywords Curriculum $\cdot$ Teacher education $\cdot$ Coronavirus $\cdot$ Covid-19 $\cdot$ Social emotional learning

Covid-19 has cast a wide shadow globally. It has impacted education at all levels, with schools closing and teachers scrambling to set up and disseminate new curricula online. In teacher education, academics face a new reality, yet lack the research to justify the pragmatic curricular changes they must make. To make matters worse, higher education curriculum, a subfield within the broader domain of education studies (Bovill and Woolmer

Linor L. Hadar

linor.hadar@beitberl.ac.il

Bracha Alpert

bracha@beitberl.ac.il

Tamar Ariav

ariavt@beitberl.ac.il

1 Beit-Berl College, Beit Berl 4490500, Israel 
2019), has received relatively little critical attention (Annala et al. 2016; Clegg 2011; Lindén et al. 2017), and those working in this area have widely divergent views about curriculum contents, scope, structure, and organization (Bridges 2000).

Within the domain of higher education more generally, Fraser and Bosanquet (2006) have identified four conceptualizations of curriculum: (1) the structure and content of a course/unit (syllabus); (2) the structure and content of a program of study; (3) students' experience of learning; (4) and dynamic and interactive processes of teaching and learning. In the first two, curriculum is seen as a product defined and documented by an instructor planning a course or program of study for students. In the third, curriculum is a context enabling student learning, and in the fourth, it is an emergent and collaborative process for student and teacher.

Expectations of twenty-first century higher education curricula are that it will facilitate students' engagement with powerful knowledge (Young 2013) and that it will prepare them to play an active role in a changing society through self-actualization, agency, critical and creative thinking, problem solving, communication, collaboration, creation, and innovation (Deng 2015; Trilling and Fadel 2009). Technological advancements and the exponential expansion of information also play a major role in shaping curriculum and instruction (Lai and Lei 2015).

However, most students already know which courses they need to take, how many credits they get for each, the subject areas they need to cover, etc., and for each course, they receive a syllabus detailing its goals, content, sequence of study, course readings and assessment methods. The syllabus functions as a contract between the instructor and the students and usually cannot be changed substantially mid-course. Thus, the scope, general contents, and sequence of both the macro-curriculum (the program of study, credits, and duration) and the micro-curriculum (the content, goals, structure, and assessment of specific courses) tend to represent a faculty-centered model (Bovill and Woolmer 2019). The curriculum choices of academics validate certain knowledges and practices over others (Bernstein 2000)—choices that focus on selection (curriculum content), sequencing (order/progression), pacing (time/credits), and evaluation (what counts). Reflecting existing understandings of curriculum (Fraser and Bosanquet 2006), these features of the higher education curriculum have not changed over many years.

This general description of higher education curriculum also applies to teacher education. In the broadest sense, a teacher education curriculum consists of courses in various subject matters (the content taught) and educational foundations and pedagogy relevant to teaching and learning processes. At the heart of it all are field experience and methods courses that deal with planning, executing, and evaluating particular units of instruction in the classroom as well as ways of thinking about content that are rooted in a pedagogical perspective and familiarity with school curriculum.

Yet, curriculum literature and studies of teacher education rarely refer specifically to the teacher education curriculum. Research in teacher education often addresses such issues as professionalism, identity, learning, knowledge, and practice (Flores 2016; Milam 2015), topics that clearly relate to curriculum but are not viewed through this lens. The lack of research in teacher education from a curricular perspective is surprising-and especially problematic during these turbulent times.

In Israel, teacher education curriculum is regulated at the state level through a framework (Council for Higher Education 2006) that defines the overarching areas of study (foundations of education, disciplinary knowledge, research methodology, pedagogy, and practice teaching), the number of credits required in each area, and the overall credits required for each program type (BEd, MTeach, postgraduate teaching certificate) and level 
(early childhood, elementary and secondary schools, special education). This mandatory framework gives each institution the freedom to create and adapt its own curriculum, but within a particular academic year, the courses and syllabi are generally preset and do not change.

\section{Technology in teacher education curriculum}

Along with these traditional approaches, technology now shapes curriculum in higher education, including teaching education. Lai and Lei (2015) define three roles of technology in the curriculum: (1) technology as content-namely, technological literacy; (2) technology as a tool-helping to implement face-to-face curriculum and providing the platform for a digital curriculum; and (3) technology as context — using technological, human, and physical resources to create synergic learning across different settings.

Teacher education curriculum utilizes all three to prepare prospective teachers for evolving teaching and learning environments. Technological literacy is integral to many programs, including computational thinking and coding. The use of technological applications, for example, enhances the use of technology as a tool (Paulsen and McCormick 2020). And technology also serves as a curricular context; student teachers (STs) can, for example, contribute ideas and materials to collaborative online forums or participate in online courses.

Because of the multitude of factors impacting learning, online learning in higher education has shown mixed results (e.g., Alpert et al. 2016; Bowen et al. 2014; Joyce et al. 2015; Means et al. 2013; Paulsen and McCormick 2020). Online courses are common in teacher education and have become almost universal during the pandemic, but they often follow the same curricular structure as regular courses. Their contents, sequencing, pacing, and evaluation are pre-planned by teacher educators, and the syllabus is a rigid learning contract.

STs do not learn the clinical component of the preservice curriculum in an online format, at least not in residential academic programs. Rather, they experience what it takes to be teachers in the field, supervised by pedagogic instructors (PIs) from the academic program and by mentor teachers in the field. This crucial element of teacher education (Flores et al. 2014) includes both practice teaching and didactic/methods courses. It is often structured progressively throughout the school year and ranges from observing and working with individual students to working with groups of students and assuming more planning responsibilities. Gradually, STs start teaching full class hours and engaging in more complex school-based activities.

PIs are responsible for the clinical component of STs' practice and methods course. They advise, escort, guide, and mentor them in schools and follow their class preparation, teaching, and reflections. They also teach both general and specific methods and didactic courses and help students with pedagogical issues, including class management, teamwork, and interactions with mentor teachers and parents.

This clinical component of the teacher education program has been strongly influenced by the Covid-19 outbreak. In Israel, the entire educational system was closed for over two months and substitute online learning modes emerged. What effect has this had on curriculum? 


\title{
Methods
}

\begin{abstract}
Aim
In this qualitative case study, we explore the effect of the coronavirus crisis on the curriculum of the clinical component of teacher education at one Israeli college. With the entire education system shut down and the move to online instruction, STs lost their physical practice sites. At the same time, the entire higher education system switched to fully online teaching. In this context, we asked whether and how the curriculum of practice teaching and didactic courses responded to the Covid-19 outbreak and the shift to online learning. What were the effects of these sweeping changes?
\end{abstract}

\section{Participants}

The study took place at a large college in central Israel whose faculty of education prepares undergraduate and graduate students to teach all school subjects to all ages, from pre-school through 12th grade in both Jewish and Arab education systems. The clinical component includes a variety of partnership models with schools. College-based teacher educators-PIs who are responsible for STs' practice teaching and the accompanying didactic and methods courses - teach this part of the preparation programs. We invited all elementary and secondary PIs to take part in the study $(\mathrm{N}=60)$. Our data are derived from the 33 PIs in the elementary and secondary departments who agreed to do so. As explained below, some of them collaborated in both a questionnaire and interview, while others volunteered to provide information for one tool only.

The PIs in our study were experienced teacher educators (mean seniority $=18.5$ years); $26(79 \%)$ had a doctorate and $7(21 \%)$ a Master's degree. Nine (27\%) were male and 24 (73\%) female. Fourteen (42\%) worked in the elementary department and $19(58 \%)$ in the secondary department. Nine (27\%) came from the Arab community and 24 (73\%) from the Jewish community. They represented multiple content areas: 14 (42\%) science and math, $11(33 \%)$ humanities and $8(24 \%)$ social sciences.

\section{Data collection}

We applied two data collection methods four to five weeks into the coronavirus crisis (by this stage, STs had experienced face-to-face teaching for one semester):

1. An open-ended questionnaire asked PIs to (a) reflect on how the Covid-19 outbreak and the shift to online learning in the college and schools affected their curriculum; (b) describe their methods and didactic classes in response to the changing conditions; and (3) explain how this change affected their teaching and their STs' learning. The questionnaire was formatted on Google-forms and sent to all PIs of elementary and secondary teacher education programs $(\mathrm{N}=60) ; 24$ completed it.

2. An email invitation to participate in a semi-structured interview was sent to all PIs of elementary and secondary teacher education programs $(\mathrm{N}=60)$. Sixteen responded and agreed to participate. (Seven of these 16 also completed the questionnaire and were not counted twice). The interviews lasted, on average, one and a half hours. Each PI was asked to detail and reflect on the curricular changes implemented as a result of Covid- 
19. Interviews were conducted using phone video calls that were recorded and then transcribed.

All participants participated voluntarily, and the college's institutional review board (IRB) approved all research procedures.

\section{Data analysis}

Data were analyzed qualitatively using grounded theory (Corbin and Strauss 2015). This accepted methodology for coding qualitative data requires analysts to create or adapt concepts from data rather than establish groupings according to an existing theory or $a$ priori categories. The data from the two sources, the questionnaire and the interviews, were first analyzed as one pool. All data were read and then reread to categorize curriculum responses to Covid-19. Similarities, differences, and complementarities across and within participants were examined. To obtain trustworthiness, we individually abstracted the preliminary categories; then, they compared notes and agreed on a list of categories. In a second phase, each of us brought examples from the data to support the categories. This refined the categories and supported their final structure. Finally, we went back to the raw data from both sources and read each corpus to ensure that these categories appeared in both.

\section{Findings}

The rapid shift to online teaching and learning created a multi-layered challenge for STs and PIs. In addition to shifting the methods course to an online format, they had to decide how to conduct practice teaching. The crucial opportunity for classroom observation and teaching, schoolwide collaboration, and intimate interaction with mentor teachers had vanished abruptly. STs' core experience became virtual, with all communications and interactions occurring online (mostly on Zoom). The curricular context shifted dramatically: The move not only affected the enacted or implemented curriculum (curriculum that is put into practice); our data suggest the shift also changed the perception of the curriculum itself.

The transition to online teaching contested the notion of how curriculum should be constructed in the future-whether it will be a fixed, pre-planned curriculum manifested in course syllabi and perceived as a contract with little flexibility (pre-planned goals, learning outcomes, learning materials, sequence of study, etc.) or a curriculum that is malleable and flexible. Curriculum malleability is demonstrated empirically in how the PIs talked about the shift in context. In fact, curriculum malleability comprised the major and overarching category of our findings, and it occurred on many levels. Within this category, two sub-categories emerged: (1) a shift of curriculum toward STs' wellbeing and social emotional learning (SEL); and (2) PIs' adaptation of teaching methods.

\section{Malleable sequence, scope, and content}

The PIs in our study considered the syllabus to be "the curriculum". For PI1, the preplanned, "safe" curriculum document had disappeared: "My syllabus is dead. It totally 
collapsed...except for very specific contents, the syllabus is dead". Now, everything was malleable - the scope, the sequence, and the contents: "I explained to my students that nothing is the same anymore and that the syllabus is changing as we go".

PI2 noted that using digital tools was previously one of many pedagogical topics, but Covid-19 has led her to restructure the sequence of things:

Now everything works backwards. We start with technology and then pour in the content. Before this crisis, technology was a tool that accompanied the content. But now it's at the core.

PI3 had similar concerns:

Each month, I build an organized activity program: who enters which classroom, what is the sequence of activities in school, when do I enter to watch my students teaching, when does each student teach...I always plan a month ahead. Now I live from one day to the next.

PI4 also pointed to changes in sequence and content:

Suddenly, there was a need to change the timeline of the course and the order of the meetings. There was a need to bring content about reforms and teacher unions and things like that. Our WhatsApp group is constantly active, although formally we are not in school. Students post articles about the situation, and we continue our Zoom discussions on WhatsApp.

In addition to imposing a restructuring of curriculum content and sequence, the Covid19 shutdown affected the curriculum's scope. PI4 said, "I had to reduce the topics to be taught as part of the didactic curriculum". PI5 noted, "I canceled two full study days on two central topics in the didactics curriculum. Instead, we engaged in reduced online activities on these topics". PI6 said:

I reduced the scope of the lesson plans the students had to prepare-in order not to burden them. I asked them to focus only on the aims and structure of the lesson and the skills to be taught but not to detail the instructional contents.

Teaching practice was fully canceled, and students could not enter classes as they were used to doing. STs depended on the goodwill of mentor teachers to invite them to their Zoom class sessions. In fact, some mentor teachers, as PI7 described, were not very welcoming:

I gently asked the mentor teachers to include the STs in their teaching. Although they included the STs in the preparation of lesson plans, short videos, presentations, and other learning materials that they used in the online meeting with the class, they did not agree to let them actually teach. The mentors asked the STs to prepare the lesson and send it to them, and the mentor teachers then taught it themselves.

When mentor teachers did not let STs teach online, a central element of the teaching practice curriculum collapsed.

A new topic entered the now-malleable curriculum: distance learning. PI4 and PI8 expanded the teaching of digital tools, digital books, materials to be found on the Web, and the practice of distance learning through Zoom and other platforms. PI9 asked her students to plan lessons for delivery in two ways: face-to-face and online: 
Generally, I went over the content list in the syllabus and checked the relevance of each item for the current situation. The non-relevant aspects were set aside...I adapted the relevant content to face to face and online lessons. I worked through the differences and asked the students to think about ways to teach both...I cannot really ignore the face-to-face aspect because next year, hopefully, they will need this.

The wealth of science materials on the Web enabled PI10 to replace real lab lessons with videos of science experiments. The shift in context to the virtual world resulted in "less knowledge...fewer face to face coping strategies with students, but much more pedagogy related to using technology in teaching". In other words, there was a balance between reduction and expansion of the curriculum in the clinical part of the teacher education program. Certain topics had to be omitted or reduced, and other topics, especially those related to digital curriculum and instruction, were introduced or expanded.

The syllabus for the didactic/methods courses and field experiences usually includes pedagogical content knowledge (PCK) and general pedagogical knowledge (GPK) (Shulman 1986). The PIs reported that although they tried to follow their syllabi, they made changes in the PCK and modes of instruction. A new category, technological pedagogical content knowledge (TCPK) (Abbit 2011; Mishra and Koehler 2006) now became a salient component of the clinical curriculum, both as a topic itself and as a means for teaching PCK and GPK. As PI11 explained:

I tried not to change the syllabus but instead to change the way I approach the content. If we planned to talk about how to build learning environments, now we talk about how to build online learning environments. This shift made me rethink and change the contents of the whole unit. The study unit has approximately the same title, but the contents changed.

Even before the coronavirus, it was clear to the PIs that digital literacy should be a more extensive part of the clinical curriculum. They used the Moodle academic digital platform of the college, some online technologies, videos, digital games, PowerPoint presentations, MOOCS, etc. Although PIs dedicated approximately one class per academic year to digital literacy, they encouraged STs to use digital practices regularly in their classroom. All PIs now understood that digital literacy was essential. As PI12 said, "There must be an online element in practice teaching”. Many other PIs acknowledged this was no longer a voluntary component-it was essential.

Other Covid-19 crisis-related contents included "teaching and learning in uncertainty" (PI13), "adapting content to technology and introducing an integrative learning model" (PI14), and "online classroom management" (PI8).

As the PIs' comments make clear, changes in sequence, scope, and contents were central to the response of the clinical curriculum to the Covid-19 crisis. A once structured curriculum now became malleable.

\section{Shift to "well-being" and SEL curriculum}

The curriculum also shifted from an emphasis on knowledge, skills, cognitive aspects, and achievements to the emotional and affective dimensions of learning. The PIs talked extensively about the nature of these changes. PI14 said, "I learned that I need to ask the STs what I need to do [so] they will have a better experience". Concern for students' well-being and SEL became a major part of curricular discourse. SEL is the process of acquiring competencies to recognize and manage emotions, develop caring and concern for others, 
establish relationships, make responsible decisions, and handle challenging situations effectively. SEL competencies comprise the foundational skills for the individual's wellbeing (CASEL 2013). PI6 explained this curricular shift: "I had to reconstruct our relationship and reduce the anxiety level...At first, I took care of their well-being, and only at a second stage could I move from the 'being' and proceed with the 'doing'-with the actual teaching work". PI5 said:

My STs were grateful that I attended to their needs. They experienced a curricular model that targets the individual needs of each one. Some shared their feelings of loneliness, burden, intensity, and loss of control. It was an effort for all of us, being surrounded by anxiety and ambiguity. It was important to create the feeling that we were all in it together. We all share this complex and challenging situation.

Some PIs felt they had to assure their STs about finishing the semester. PI16 explained:

Many students wrote to me about their worries. They were worried that they would not be able to finish the academic year and their practice teaching because of the school shutdown. I calmed them down and explained that they will be able to finish their academic duties. We keep on corresponding on personal issues.

Once the PIs began to attend to their students' well-being, the scope of their curriculum expanded. For example, PI3 introduced SEL contents and activities:

We had three Zoom meetings in which we first talked about their coping and their experience. We introduced two circles: influence and concern. We talked about these circles and about the ways they affect our lives. Our goal is that the influence circle will be much greater than the concern circle. People are concerned now, but it's more important to influence. This content empowered them to cope with the situation.

Attending to students' well-being was also evident in the flexible scheduling of class meetings. PI4 said:

I was super flexible with the meeting schedules. One day we had our meeting at 9 pm, after the STs' children were sleeping. Together we decided that this is the best time to meet. It is really hard to keep the usual time frame. It is impossible to sit in front of the screen for one and a half hours. It's easy to wonder and disappear. Therefore, I try to shorten our meetings...I also integrate breaks and small-group discussions in my lessons. What I expect the ST do with their own students became part of my own teaching.

PI7 mentioned: "I am flexible about the STs' attendance in the meetings and also how much they manage to practice teaching online in school".

Cultural background demanded additional flexibility. Some PIs said most of their Arab female STs refused to turn on the video during the meetings. Arab society is traditional and expects a certain female modesty. One way of attending to STs' well-being was to respect such cultural restrictions. PI7, a male instructor, explained: "In our Zoom meetings, I cannot see the female Arab STs...They rejected being seen online, and I agreed to that".

To attend more fully to their STs' well-being, PIs opened online meetings with questions like: "How are you? How are you feeling? What are you going through?" By starting each meeting with caring questions (Noddings 2012), they felt their curriculum was being responsive to the crisis. As STs shared their fears, frustrations, and concerns, PIs created more personal relationships than usual with them. PI13 said: 
When students turned their camera on, we saw not only where they sit, we saw the house, the dog, the children. This would never have happened in a normal semester. In many ways, there is more closeness among the STs and myself.

Feelings became integral to the curriculum, as PI5 explained:

We have many conversations in which we share our feelings. What is going on at home? How are the children? What do you think about the situation? Everything became more personal. Each person exposed their feelings... One person just broke up with his girlfriend, another is a stay-at-home dad... We talked about different ways in which people cope. I learned that I have very interesting people in the group.

PI14 described how his STs shared their feelings about their practice teaching:

One student was so nervous before teaching her students on Zoom. She said, "I'm desperate and I don't know what to do". I spoke to her. After the lesson, she wrote back and said that she was anxious, but it was fun".

PI14 also said many STs talked about the pressure caused by the number of assignments they received, their worries about completing the semester, and whether they would ultimately find work.

As our findings make clear, the curriculum responded to the Covid-19 crisis by shifting attention to emotional and social issues, with the student teacher now at the center of a malleable curriculum.

\section{Adaptation of teaching methods}

The necessity to quickly move to online teaching and learning yielded a wealth of teaching strategies, with an emphasis on technique rather than content. The main purpose of these strategies was to model online instruction when STs were not physically present. Instructional models and methods ("how to teach") are always a central part of the teacher education curriculum, specifically the clinical part. Nevertheless, the "how" is always connected to the "what" - the goal or content. In our data, under the radically new conditions, the "how" dominated the "what" of the curriculum. When the PIs explained the ways their curriculum has responded to the Covid-19 shutdown, they emphasized the instructional models they used:

I gave them an individual or small-group off-line assignment to compose math problems and then arranged a group meeting on Zoom to present and discuss them. (PI11)

I implemented a flipped classroom model: Student teachers individually observe an online lesson, and we then meet on Zoom to discuss it. (PI17)

PI6 noted that the STs' mindset not only shifted to the "how" but neglected the "what":

Most of our learning revolved around the technology as a teaching tool. How am I dealing with it? Whenever I tried to push it forward to How does using this tool connect with your goals? or Why did you choose this tool to teach that content? the student teachers shut themselves down. Only at a later stage did they begin to realize that the technology is the instructional method and not the goal.

PI14 pointed to a similar shift: "All they cared about is whether the technology would work and that all their students would attend. They didn't care at all about their teaching 
plan, the contents, the curriculum, or the goal". PI6's and PI14's curriculum, like so many others, responded to the crisis by focusing on how to teach with technology.

To respond to the contextual shift to online learning, PIs used modeling as a salient means of teaching and learning - an example of the shift from the what to the how. How the PIs taught was expected to be an example for their STs. As PI11 noted:

I modeled an instructional method and specifically asked the STs to use it in their classroom. I modeled specific problematic issues that are difficult for both the ST and the students in school.

PI16 said:

Our modeling is really important. We need to show them how to work on visualization, specifically in Zoom; to emphasize the students' multiple intelligences, specifically in those cases when the teacher sits behind a screen; and to show them variations in instructional methods.

For some PIs, the shift from face-to-face classes to digital instruction had a devastating effect, while for others, it was an eye-opener.

\section{Disadvantages}

PI11 pointed to the difficulty of following students' thinking process when teaching online math, noting the challenges "to having them experience various physical learning environments, to have a fruitful mathematical discourse, and to teach differentially". PI20 noted what he called "inequality in teaching":

You don't really hear the weak student teachers, and I think that creates gaps in the group. The strong ones control the discussion. In the physical classroom, I can "read" their faces. I had to adapt my instruction to this.

Challenges to teaching specific subject matter were also mentioned. As PI8 explained, "In physics, a critical activity is lab work and other demonstrations. They don't touch any equipment now, so you need to think of instructional alternatives".

\section{Opportunities for teaching}

Despite its limitations, almost all PIs found some advantages in online teaching, and their curricular response included new and creative teaching methods:

My teaching is transformed. It's much more creative...I need to use the blackboard, so I painted one wall in my house with special paint and I write on it and screen it to the STs. (PI14)

Online teaching opened never-ending spaces of knowledge. We enjoy immediate access to many sites and have deep discussions about what we read there. At school, there is never time to deeply explore an issue. (PI5)

PI8 directed her STs to teach only ten students at a time, not 30, the size of the typical student classroom. She was enthusiastic about the possibilities of online teaching, recommending that from now on, practice teaching have an online teaching component: 
It's a great experience. The curriculum should respond accordingly in the future. We can keep on using this tool parallel to our daily routine. The student teachers won this semester... and our curriculum needs to respond to this accordingly (PI8).

Many other PIs pointed to the future curricular possibilities of online teaching. PL22 said:

This crisis will change everything. We have always used technology in our teaching but not as extensively as now... I don't yet understand everything that technology has to offer, but I assume that nothing will stay the same.

The PIs went beyond contemplating their teaching during the crisis to envisioning how teaching and learning might change in the post-coronavirus period. While all of the PIs felt that face-to-face teaching and learning could not be replaced, they acknowledged that online teaching has untapped potential and believed the Covid-19 crisis would have longterm and lasting effects on curriculum.

\section{Discussion}

In this case study, we explored how PIs in one Israeli college, responsible for the clinical element of the teacher education curriculum, responded to Covid-19. The curriculum changed dramatically in sequence, scope, and contents. Two specific domains of change were the focus on students' well-being/SEL and the adoption of new teaching methods. A malleable curriculum responded to the STs' needs and took full advantage of technology.

Our study shows how the Covid-19 breakout transformed the curriculum from the traditional pre-planned and structured syllabus to a more responsive, dynamic, and malleable curriculum. It shifted from a more rigid to a more negotiated and flexible curriculum (Fraser and Bosanquet 2006). Our findings suggest that the intended curriculum, reflected in the PIs' initial perceptions and planning, has also changed. PIs thought these changes, though responding specifically to the pandemic in an ad hoc fashion, would have effects on future intended curriculums.

One possible lasting effect is the shift from a pre-planned, documented curriculum to a dynamic, collaborative process of learning with a strong emphasis on SEL and the wellbeing of STs. PIs admitted that they would not be able to go back to "business as usual", and STs experienced new forms of practice teaching and dialog with their PIs.

This is not entirely new, as there has been growing interest in students' social and emotional competence (Durlak et al. 2011; Durlak 2015; Eccles and Roeser 2011; OECD 2018). In their extensive study, Schonert-Reichl et al. (2015) found that teacher education curriculum does adequately emphasize SEL. Other studies say many programs ignore the importance of promoting the SEL of STs (Jones et al. 2013; Schonert-Reichl et al. 2015). This area was slow to be adopted by teacher educators in Israel but received a strong push with the coronavirus shutdown. Our findings show Covid-19 triggered a transformation in which the dominant curricular response to the crisis for most PIs was the well-being and SEL of their STs.

Although more attention is being paid to different aspects of SEL and well-being in teacher education (e.g., Bamber and Schneider 2016), the teacher education curriculum needs to continue to cultivate and promote STs' social and emotional competence and well-being.

Our findings also indicate a shift in perceptions of online learning. Online learning technology became the context in which all learning occurred, and this reshaped PIs 
instructional approaches. Doyle and Carter (2003) argue that a basic assumption of teacher education curriculum is that knowing precedes doing and that action is a consequence of knowing. Our findings show how this sequence was reversed, with doing and action becoming more important than knowing. The PIs' emphasis on "how" rather than "what" shaped the learning experience of STs and put the onus squarely on the integration of technology into the curriculum (Lai and Lei 2015).

Technology interacted with curriculum at both the context and the tool level (Lai and Lei 2015). PIs gave less attention to technology as content (learning about technology) and more to technology as tool (using technology). Our findings show how curriculum responds when technology becomes the context in which learning occurs. Currently, research does not fully consider the technological context of teacher education. More research is needed to understand how to capitalize on technologies that support learning and integrate them into the curriculum. If nothing else, Covid-19 offers an opportunity to explore these issues.

This case study opens a window onto curricular adaptations in teacher education in the core component of clinical practice at a time when the planned and structured curriculum ceased to function. Encouragingly, our PIs suggested that curriculum is an ongoing, dynamic process and is responsive to changing conditions. Even more noteworthy, perhaps, PIs changed their understanding of what a curriculum is and what it could and should be. These perceptions of curricular malleability and its experiential dimension emerged only a few weeks after the start of the coronavirus crisis.

As in any case study, the findings are contextual and not generalizable. However, some of these findings may be found in other teacher education programs. This study only starts a dialog about how teacher education curriculum responded to the COVID-19 breakout; others need to weigh in and perhaps broaden the investigation. For example, is enhanced attention to STs' well-being visible in various contexts? Further, we view this as an opportunity to explore all the ways teacher education curriculum needs to change to prepare the next generation of teachers for the complexities of their profession.

Our study provides a practical, real-time description of changes the coronavirus pandemic caused in the clinical curriculum in teaching education. It shows the relevance of curriculum studies within educational research (Garcia-Huidobro 2018) and brings curriculum theorizing closer to educators' concrete praxis. For a concept that underpins the preparation of the next generation of teachers, teacher education curriculum has not received as much attention as it deserves. We hope this study will trigger more research in this area.

\section{References}

Abbit, J. T. (2011). Measuring technological pedagogical content knowledge in preservice teacher education: A review of methods and instruments. Journal of Research and Technology in Education, 43(4), 281-300.

Alpert, W. T., Couch, K. A., \& Harmon, O. R. (2016). A randomized assessment of online learning. American Economic Review, 106(5), 378-382.

Annala, J., Lindén, J., \& Mäkinen, M. (2016). Curriculum in higher education research. In J. Case \& J. Huisman (Eds.), Researching higher education: International perspectives on theory, policy and practice (pp. 171-189). London: Society for Research into Higher Education \& Routledge.

Bamber, M. D., \& Schneider, J. K. (2016). Mindfulness-based meditation to decrease stress and anxiety in college students: A narrative synthesis of the research. Educational Research Review, 18, 1-32.

Bernstein, B. (2000). Pedagogy, symbolic control and identity: Theory, research, critique. Lanham, MD: Rowman \& Littlefield.

Bovill, C., \& Woolmer, C. (2019). How conceptualisations of curriculum in higher education influence student-staff co-creation in and of the curriculum. Higher Education, 78, 407-422. 
Bowen, W. G., Chingos, M. M., Lack, K. A., \& Nygren, T. I. (2014). Interactive learning online at public universities: Evidence from a six-campus randomized trial. Journal of Policy Analysis and Management, 33(1), 94-111.

Bridges, D. (2000). Back to the future: The higher education curriculum in the 21 st century. Cambridge Journal of Education, 30(1), 37-55.

Clegg, S. (2011). Cultural capital and agency: Connecting critique and curriculum in higher education. British Journal of Sociology of Education, 32(1), 93-108.

CASEL [Collaborative for Academic, Social, and Emotional Learning] (2013). Effective social and emotional learning programs-Preschool and elementary school edition. https://casel.org/preschooland-elementary-edition-casel-guide/.

Corbin, J., \& Strauss, A. (2015). Basics of qualitative research: Techniques and procedures for developing grounded theory (4th ed.). Thousand Oaks, CA: Sage.

Deng, Z. (2015). Organization and sequencing of subject matters. In M. F. He, B. D. Schultz, \& W. H. Schubert (Eds.), The SAGE guide to curriculum in education (pp. 78-86). Thousand Oaks, CA: Sage.

Doyle, W., \& Carter, K. (2003). Narrative and learning to teach: Implications for teacher-education curriculum. Journal of Curriculum Studies, 35(2), 129-137.

Durlak, J. A. (Ed.). (2015). Handbook of social and emotional learning: Research and practice. New York, NY: Guilford.

Durlak, J. A., Weissberg, R. P., Dymnicki, A. B., Taylor, R. D., \& Schellinger, K. B. (2011). The impact of enhancing students' social and emotional learning: A meta-analysis of school-based universal interventions. Child Development, 82(1), 405-432.

Eccles, J. S., \& Roeser, R. W. (2011). School and community influences on human development. In M. H. Bornstein \& M. E. Lamb (Eds.), Developmental science: An advanced textbook (6th ed., pp. 571-643). New York, NY: Psychology Press.

Flores, M. A. (2016). Teacher education curriculum. In J. Loughran \& M. L. Hamilton (Eds.), International handbook of teacher education (pp. 187-230). Dordrecht: Springer.

Flores, M. A., Santos, P., Fernandes, S., \& Pereira, D. (2014). Pre-service teachers' views of their training: Key issues to sustain quality teacher education. Journal of Teacher Education for Sustainability, 16(2), 39-53.

Fraser, S., \& Bosanquet, A. (2006). The curriculum? That's just a unit outline, isn't it? Studies in Higher Education, 31(3), 269-284.

Garcia-Huidobro, J. C. (2018). Addressing the crisis in curriculum studies: Curriculum integration that bridges issues of identity and knowledge. The Curriculum Journal, 29(1), 25-42.

Higher Education Council (2006). Decision of the Higher Education Council from 21.11.2006, regarding "Guidelines for teacher training in higher education institutions in Israel". Ariav committee report. https://che.org.il/wp-content/uploads/decisions/138844.

Jones, S. M., Bouffard, S. M., \& Weissbourd, R. (2013). Educators' social and emotional skills vital to learning. Phi Delta Kappan, 94(8), 62-65.

Joyce, T., Crockett, S., Jaeger, D. A., Altindag, O., \& O'Connel, S. D. (2015). Does classroom time matter? Economics of Education Review, 46, 44-67.

Lai, C., \& Lei, J. (2015). The technological milieu. In M. F. He, B. D. Schultz, \& W. H. Schubert (Eds.), The SAGE guide to curriculum in education (pp. 335-343). Thousand Oaks, CA: Sage.

Lindén, J., Annala, J., \& Coate, K. (2017). The role of curriculum theory in contemporary higher education research and practice. In J. Huisman \& M. Tight (Eds.), Theory and method in higher education research (pp. 137-154). Bingley, UK: Emerald Publishing.

Means, B., Toyama, Y., Murphy, R., \& Baki, M. (2013). The effectiveness of online and blended learning: A meta-analysis of the empirical literature. Teachers College Record, 115, 1-47.

Milam, J. L. (2015). Teacher education curriculum. In M. F. He, B. D. Schultz, \& W. H. Schubert (Eds.), The SAGE guide to curriculum in education (pp. 198-206). Thousand Oaks, CA: Sage.

Mishra, P., \& Koehler, M. J. (2006). Technological pedagogical content knowledge: A framework for teacher knowledge. Teachers College Record, 108(6), 1017-1054.

Noddings, N. (2012). The caring relation in teaching. Oxford Review of Education, 38(6), 771-781.

OECD [Organization for Economic, Co-operation and Development] (2018). The future of education and skills: Education 2030. Paris: OECD. http://www.oecd.org/education/2030-project/contact/ E2030_Position_Paper_(05.04.2018).pdf.

Paulsen, J., \& McCormick, A. (2020). Reassessing disparities in online learner student engagement in higher education. Educational Researcher, 49(1), 20-29. 
Schonert-Reichl, K. A., Hanson-Peterson, J. L., \& Hymel, S. (2015). SEL and preservice teacher education. In J. A. Durlak (Ed.), Handbook of social and emotional learning: Research and practice (pp. 406-421). New York, NY: Guilford.

Shulman, L. S. (1986). Those who understand: Knowledge growth in teaching. Educational Researcher, 15(2), 4-14.

Trilling, B., \& Fadel, C. (2009). 21st century skills: Learning for life in our times. San Francisco, CA: Wiley.

Young, M. (2013). Overcoming the crisis in curriculum theory: A knowledge-based approach. Journal of Curriculum studies, 45(2), 101-118.

Publisher's Note Springer Nature remains neutral with regard to jurisdictional claims in published maps and institutional affiliations.

Linor L. Hadar is an associate professor and head of the curriculum studies lab at Beit Berl College, in Israel. She developed and now heads a new Master's in Teaching program for primary education. Her research on curriculum and pedagogy focuses on thinking education, teacher education, communal learning, and the professional learning of teachers and teacher educators. Her publications include: "Talk about student learning: Promoting professional growth among teacher educators" (Teaching and Teacher Education, 2016); "Individual growth and institutional advancement: The in-house model for teacher educators' professional learning" (Teaching and Teacher Education, 2018); "Professional learning and development of teacher educators" (International Handbook of Research on Teacher Education, 2017). With David L. Brody, she wrote Teacher educators' professional learning in communities (Routledge, 2017).

Bracha Alpert is an associate professor of education at Beit Berl College. She holds a master's degree from Tel Aviv University in educational studies and a doctorate from Stanford University in Curriculum and Teacher Education. For over three decades, her research, writing, and lecturing have focused on curriculum, instruction, and qualitative research. From 2013-2019 she served as dean of the faculty of education at Beit Berl. Currently, she also leads workshops on qualitative research methods and writing at the Mofet Institute in Tel Aviv.

Tamar Ariav is an associate professor of education and, since 2008, president of Beit Berl College. She holds a master's degree from Tel Aviv University and a doctorate from the University of Pennsylvania, both in curriculum and instruction. Beginning her career as a schoolteacher in Israel, Germany, and the United States, she joined Beit Berl to teach curriculum planning, instructional methods and evaluation. Her research over several decades has focused primarily on teacher education policy, with an emphasis on clinical models for practice teaching. Tamar has been a member of the Council for Higher Education in Israel and chaired the Committee for New Frameworks in Teacher Education, organizations that continue to set professional standards for teacher training in Israel. 